\title{
ANTIOXIDANT ACTIVITY OF SOME NEWLY PREPARED SYMMETRICALLY AZO DYES DERIVED FROM SULFA DRUGS
}

\author{
MUNTHER ABDULJALEEL MUHAMMAD-ALI*, HUSSAM HAMZA SALMAN, EKHLASQANBER JASIM \\ Department of Pharmaceutical Chemistry, College of Pharmacy, Basrah University, Basrah, Iraq. Email: muntheralamery@yahoo.com \\ Received: 17 October 2018, Revised and Accepted: 22 December 2018
}

ABSTRACT

Objective: Sulfa drugs (sulfonamides) were the first type of drugs largely medically used for preventive and chemotherapeutic agents against various types of diseases. To the date, much research has been directed toward the synthesis sulfa drug derivatives such as azo-sulfa drug compounds. The aim of the present study is to synthesize of azo-sulfa compounds as antioxidant agents.

Methods: First, three of sulfa drugs react with 4-methoxy-1,2-Naphthoquinone in aqueous medium by stirring at room temperature to give symmetrically azo-sulfa compounds. The colored compounds which formed were examined their structures by infrared and proton nuclear magnetic resonance spectral techniques.

Results:Threesymmetricallyazo-sulfacompoundsweretestedasantioxidantagentscompared withascorbicacid(AA)using2,2-diphenyl-1-picrylhydrazyl method. The results indicated that these compounds had good activities (57.79-73.69\%) at 30 $\mu \mathrm{g} / \mathrm{ml}$, which had less activity than AA (81.34\%) at the same concentration. These results referred the $\mathrm{IC}_{50}$ which had values $(15.23-21.35 \mu \mathrm{g} / \mathrm{ml})$, whereas $\mathrm{AA}$ had $7.59 \mu \mathrm{g} / \mathrm{ml}$.

Conclusion: Attachment of heterocyclic rings containing nitrogen and oxygen (isoxazole) on the azo-sulfa compounds can enhance the antioxidant activity as compared with the heterocyclic rings containing nitrogen only (pyrimidine) and without heterocyclic rings, which enhanced the lipophilicity which may increase the bioavailability and efficacy of the drug.

Keywords: Antioxidant, Sulfonamide, Azo compounds.

(C) 2019 The Authors. Published by Innovare Academic Sciences Pvt Ltd. This is an open access article under the CC BY license (http://creativecommons. org/licenses/by/4. 0/) DOI: http://dx.doi.org/10.22159/ajpcr. 2019.v12i2.30326

\section{INTRODUCTION}

Sulfa compounds have been used widely for a long time in the treatment of diverse diseases [1]. In the medicinal uses, there are more than 30 drugs which are commercial used in markets, including antihypertensive, antibacterial, antiprotozoal, antifungal, and anti-inflammatory [2].

One of the important clinically used sulfa drugs was called prontosil which is azo-sulfa drug that gave protective action against streptococci in animals. Prontosil has two effective features, and it was active in vivo, while it is ineffective in vitro. These features led to the fact that this drug was not the active $[3,4]$. Azo dyes have wide applications, these compounds have been used as cosmetics because of more stable than natural colours and used as pharmaceutical products [5]. According to stability, azo-dyes are stable in different ranges of $\mathrm{pH}$, they do not vanish when exposed to oxygen or light, and some of them are soluble in water. However, azo dyes have not the ability to dissolve in fat or oily phases [6].

Antioxidants are organic or inorganic compounds have ability to reduce or limit oxidative damage effects in the structures of biological tissues by passivizing free radicals. These classes of compounds may be added to the foods to increases their shelf life by process called lipid peroxidation retardation. Accordingly, these types of compounds have been used in wide area as food additives to avert the degradation of food, and they play a significant role to prevent many diseases and aging which lifestyle-related, being closely related to the reactive oxygen species (ROS) and lipid peroxidation formation in the body [7-9]. Antioxidant compounds are species widely utilized against the free radicals which reduce oxidative stress in the cell. Natural and chemical sources may be containing these antioxidant compounds [10]. 2,2-diphenyl-1-picrylhydrazyl (DPPH) tests have been widely applied to antioxidant activity screening because this class of compounds can accommodate many tested samples in a short time and sensitive for detecting active ingredients at low concentrations [11]. When DPPH radicals face the materials with proton donating such as an antioxidant, it would be scavenged and the absorbance is reduced. Thus, the DPPH radicals were used by many researchers to assay the scavenging activity of some synthesized and natural compounds [12].

The present study includes the synthesis and characterization of three types of symmetrically azo-dyes which derived from sulfa drugs and tested them as synthesized antioxidant compounds using DPPH method. Moreover, the effect of different concentrations of the compounds on the antioxidant activity compared with standard antioxidant drug (ascorbic acid [AA]).

\section{MATERIALS AND METHODS}

Materials

1. The chemicals used were procured from the following companies, sulfa drugs and 2,2'-diphenylpicryl-1-hydrazyl (DPPH) from Sigma-Aldrich Chemical Co. AA from Merck Ltd. Ethanol was analytical grade from SD fine chemicals Ltd., Mumbai, India.

2. Melting points were determined on the uncorrected open capillary tube on Campbell Melting Point Apparatus.

3. Infrared (IR) spectra were taken using Fourier-transform IR Shimadzu model 8400 spectrophotometer and KBr disk at Pharmaceutical Chemistry Department, College of Pharmacy, Basrah University. Only principal peaks are reported and expressed in $\mathrm{cm}^{-1}$.

4. Proton nuclear magnetic resonance spectra $\left({ }^{1} \mathrm{H}-\mathrm{N} M R\right)$ were recorded on Bruker model ultra-shield $400 \mathrm{MHz}$ 
spectrophotometers (Switzerland) at Tehran University, Iran. Chemical shifts are expressed as $\delta$ value (ppm), and dimethyl sulfoxide (DMSO)-d6 was used as a solvent and tetramethylsilane as an internal standard.

5. While citing ${ }^{1} \mathrm{H}$-NMR data, the following abbreviations have been used S (singlet), d (doublet), t (triplet), and $\mathrm{m}$ (multiplet).

6. The CHNS analysis measurements for the synthesized compounds were performed at the Analytical Laboratory of Tehran University, Iran, using EuroVector model EA3000A (Italy).

7. Spectral and absorbance measurements were made with a Jena Model 1100, UV-Visible spectrophotometer (Germany) in Pharmaceutical Chemistry Department, College of Pharmacy, Basrah University. Wavelengths are expressed as $\mathrm{nm}$.

\section{Synthesis of compounds}

An aqueous solution of 4-methoxy-1,2-naphthoquinone ( 0.001 mole) in small amount of water was stirred on magnetic stirrer achieved to complete dissolved solution. Sulfa drugs (sulfisoxazole, sulfamerazine, or sulfaguanidine $)(0.002$ mole $)$ was added gradually by small amounts for a period of $15 \mathrm{~min}$ to the above aqueous solution at room temperature with vigorously stirring. After complete addition, the mixture was stirred for further time (about 15-30 min) at room temperature and the resulting product was formed. The bright colored solid precipitate of desired product was filtered off and washed with cooled mixture of water and methanol. The product was recrystallized from $\mathrm{H}_{2} \mathrm{O}$ : DMF $(2: 8)$ and dried under vacuum [13]. The physical properties are listed in Table 1.

\section{Antioxidant Activity}

Briefly, solution of DPPH with concentration $0.1 \mathrm{mM}$ was prepared using ethanol as solvent. From the solution above, $0.5 \mathrm{ml}$ was withdrawn and added to $1.5 \mathrm{ml}$ of azo-sulfa compound solution in ethanol at different concentrations $(5-30 \mathrm{~g} / \mathrm{ml})$. The resulting mixture was shaken vigorously by mechanical shaker and left to stand for 30 min incubation period at room temperature. The absorbance of the clear resulting solution was measured at $517 \mathrm{~nm}$ using ethanol as blank. The lowering in absorbance of the resulting mixture indicates a higher activity of DPPH free radical scavenging. Azo-sulfa compound concentration providing $50 \%$ inhibition $\left(\mathrm{IC}_{50}\right.$ ) was calculated using the graph by plotting inhibition percentage against azo-sulfa compound concentration. Ascorbic acid (AA) was used as positive controls, and all tests were carried on triplicates [14].

The capability to scavenge the DPPH radical was calculated using the following equation [8]:

DPPH scavenging Controlabsorbance-Sample absorbance effect $(\%)=\quad$ Controlabsorbance

\section{Statistical analysis}

Data are expressed as a mean \pm SD. Total variations present in a set of data were estimated by one-way analysis of variance and comparisons were made between the treated groups. All data were analyzed using Duncan's multiple range test. $P<0.05$ was considered as the level statistical significance.

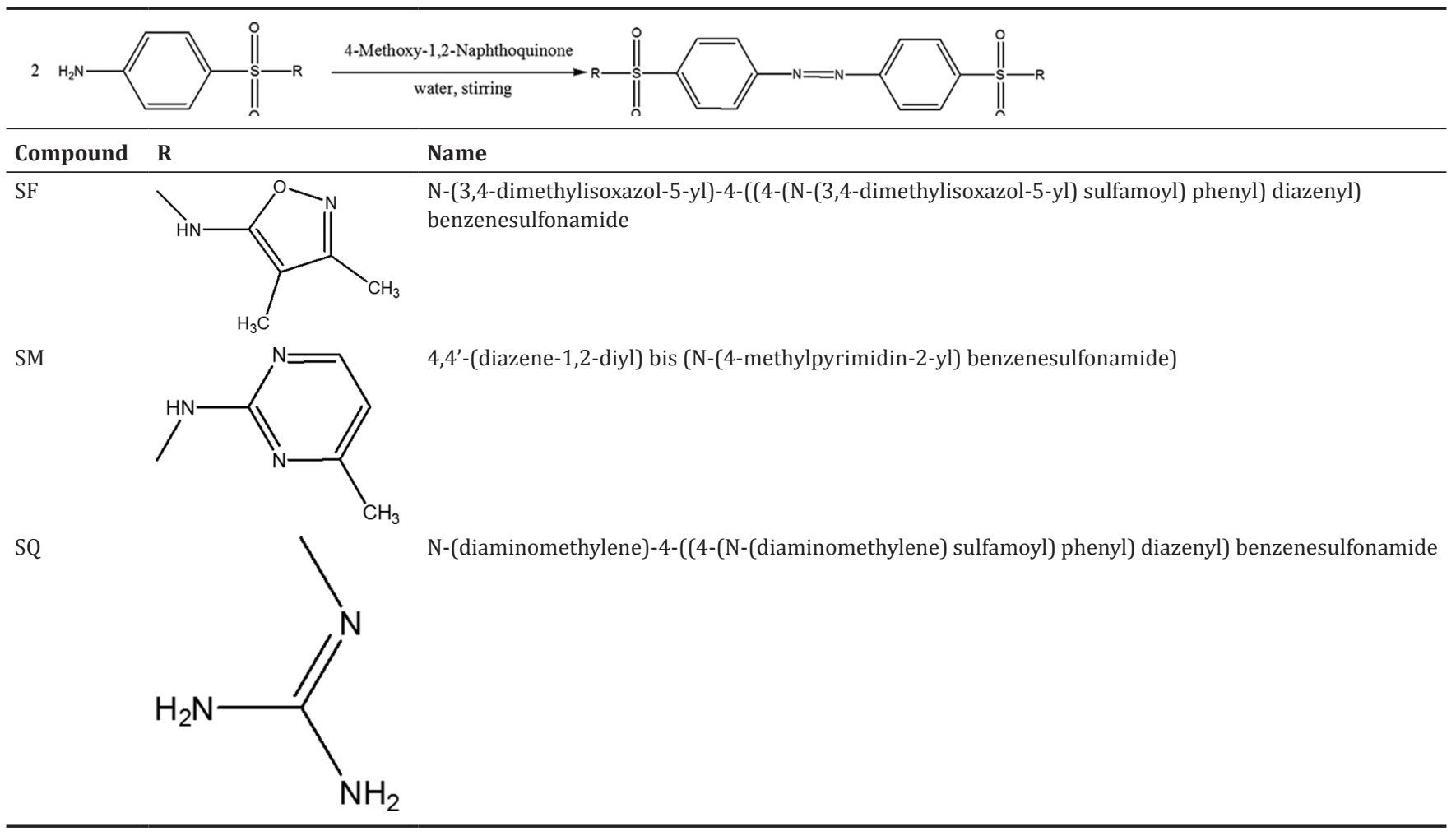

Table 1: The characterization of the prepared azo compounds

\begin{tabular}{|c|c|c|c|c|c|c|c|c|c|}
\hline \multirow[t]{2}{*}{ Compound } & \multirow{2}{*}{$\begin{array}{l}\text { Molecular } \\
\text { formula }\end{array}$} & \multirow{2}{*}{$\begin{array}{l}\text { Molecular } \\
\text { weight }(\mathrm{g} / \mathrm{mol})\end{array}$} & \multirow{2}{*}{$\begin{array}{l}\text { Crystal } \\
\text { Color }\end{array}$} & \multirow{2}{*}{$\begin{array}{l}\text { Molecular } \\
\text { pressure }\left({ }^{\circ} \mathrm{C}\right)\end{array}$} & \multirow[t]{2}{*}{ Yield (\%) } & \multicolumn{4}{|c|}{ Elemental analysis found (Calcd.) } \\
\hline & & & & & & $\mathrm{C} \%$ & H\% & N\% & S\% \\
\hline SF & $\mathrm{C}_{22} \mathrm{H}_{22} \mathrm{~N}_{6} \mathrm{OS}_{2}$ & 530.58 & Red & 170 & 87 & $49.80(48.25)$ & $4.18(4.02)$ & $15.84(16.24)$ & $12.09(12.21)$ \\
\hline SM & $\mathrm{C}_{22}^{22} \mathrm{H}_{20} \mathrm{~N}_{8} \mathrm{O}_{4} \mathrm{~S}_{2}^{2}$ & 524.58 & Orange & 230 dec. & 82 & $50.37(49.54)$ & $3.84(3.68)$ & $21.36(21.61)$ & $12.23(13.02)$ \\
\hline SQ & $\mathrm{C}_{11}^{22} \mathrm{H}_{16} \mathrm{~N}_{\mathrm{O}} \mathrm{O} \mathrm{S}_{2}$ & 424.46 & Deep red & 191 & 79 & $39.62(40.56)$ & $3.80(3.74)$ & $26.40(25.88)$ & $15.11(15.43)$ \\
\hline
\end{tabular}




\section{RESULTS AND DISCUSSION}

\section{${ }^{1} \mathrm{H}$-NMR spectra}

${ }^{1} \mathrm{H}$-NMR spectra of the prepared azo dyes were performed in deuterated DMSO solutions with tetramethylsilane as an internal standard. All these spectra showed a peak at $2.5 \mathrm{ppm}$ which was due to DMSO solvent, and some spectra showed a sharp peak at $3.33 \mathrm{ppm}$ due to dissolved water in DMSO $[15,16]$. Figs. 1-3 represent the ${ }^{P 1 P} \mathrm{H}-\mathrm{NMR}$ spectra of the azo compounds and Table 2 represents the data of Figs. 1-3.

Figs. 1-3 represent the ${ }^{1} \mathrm{H}-\mathrm{NMR}$ spectra of the three azo compounds. Two of these compounds exhibited characteristic aliphatic systems as follows; compound SF gave two singlet signals at 2.268 and $2.284 \mathrm{ppm}$ which related to twelve protons of four methyl groups in isoxazole rings. The second compound SM gave two singlet signals at 2.293 and $2.328 \mathrm{ppm}$ related to six protons of the - $\mathrm{CH}_{3}$ groups in pyrimidine rings. The compound $\mathrm{SQ}$ is lacked to these types of aliphatic protons which not give signals in the high field.

For the compounds SF and SM, there are signals at low field which were represented by singlet signals due to proton of $-\mathrm{NH}$ - group of sulfa fragment at 10.945 and $11.372 \mathrm{ppm}$, respectively. The third compound SQ showed broad signal at $5.717 \mathrm{ppm}$ related to protons of $-\mathrm{NH}_{2}$ groups in the aliphatic moiety.

Multiplet signals are in the range $6.352-8.299 \mathrm{ppm}$ which attributed to twelve protons of the aromatic systems of phenyl and heterocyclic rings for the compound SF, as shown in Table 2, whereas, for the compounds SM and SQ, there are multiplet signals in the range of 6.352-8.293 ppm and $6.233-8.219 \mathrm{ppm}$ which attributed to the protons of phenyl rings for compounds SM and SQ, respectively, as shown in Table 2 .

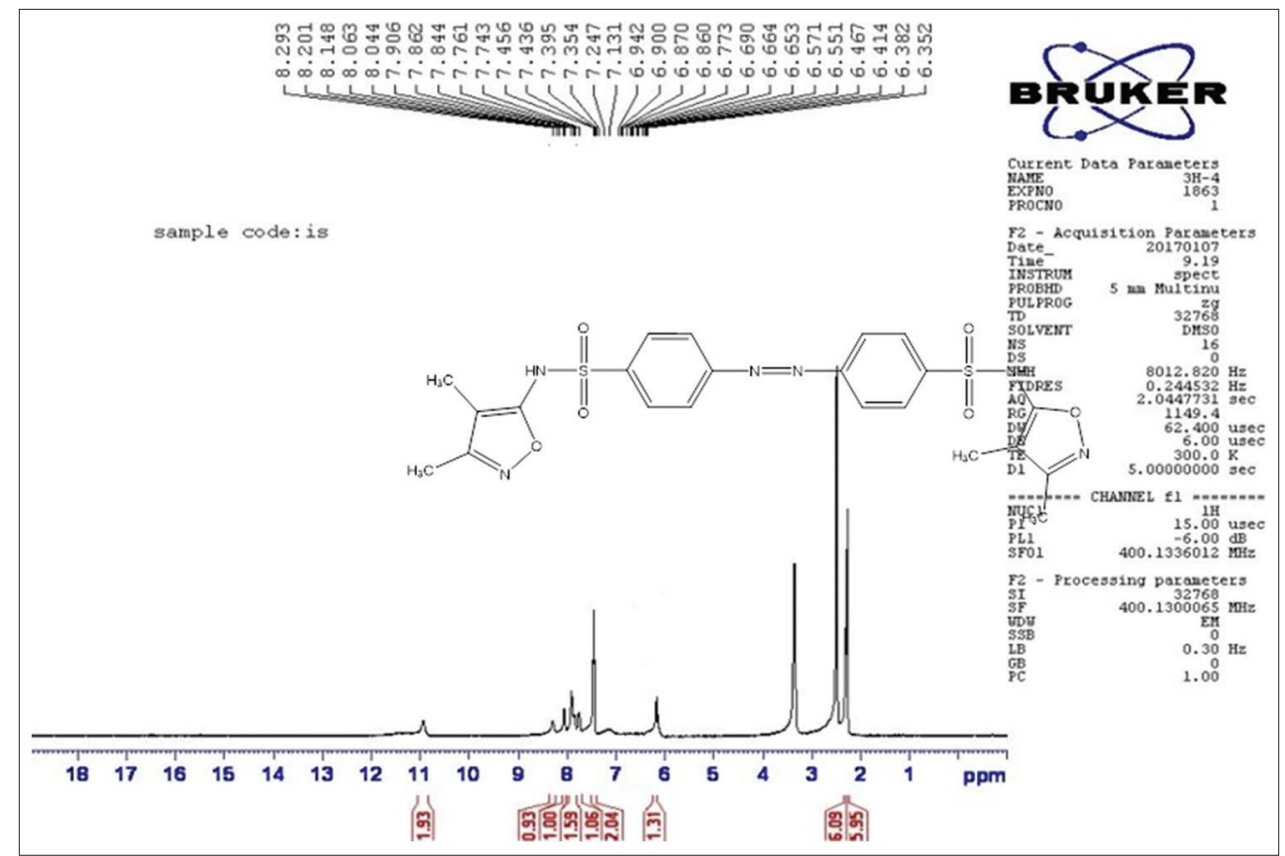

Fig. 1: ${ }^{1} \mathrm{H}$-nuclear magnetic resonance spectrum of compound SF

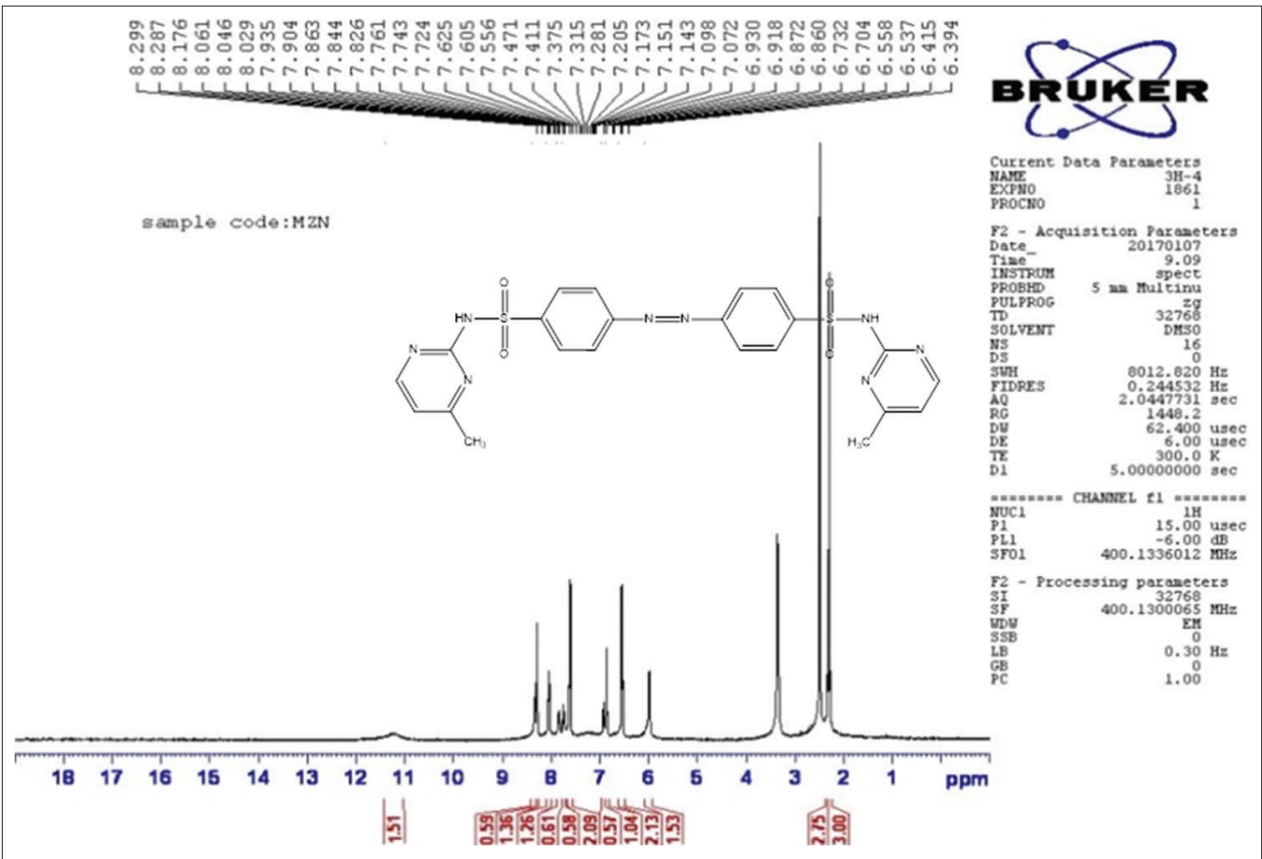

Fig. 2:1 ${ }^{1} \mathrm{H}$-nuclear magnetic resonance spectrum of compound SM 


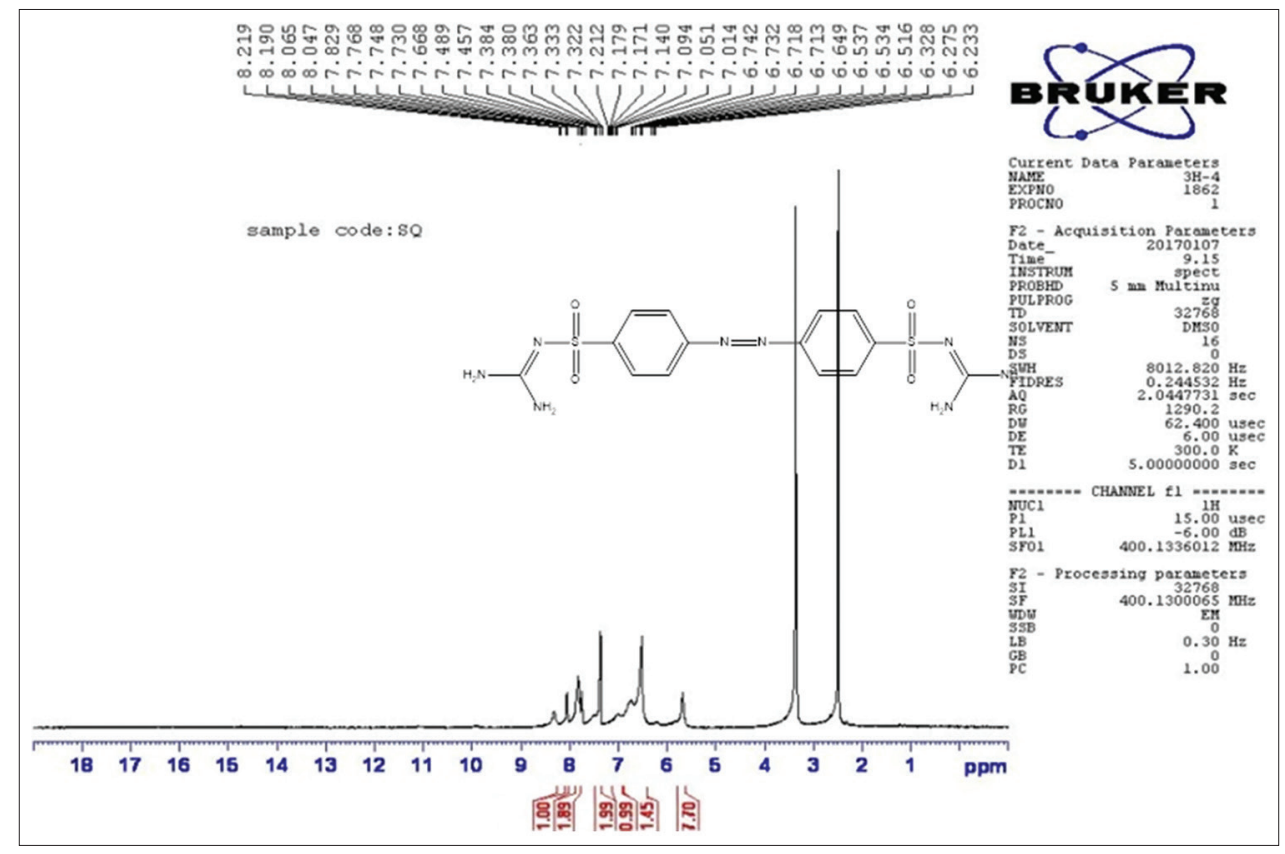

Fig. 3: ${ }^{1} \mathrm{H}$-nuclear magnetic resonance spectrum of compound $S Q$

Table 2: ${ }^{1} \mathrm{H}$-nuclear magnetic resonance spectrum data of synthesized compounds

\begin{tabular}{lllll}
\hline Compound & $\mathbf{d ~ p p m}$ & & \\
\cline { 2 - 5 } & $\mathbf{- \mathbf { C H } _ { 3 }}$ & $-\mathbf{N H}_{2}$ & Aromatic system & -NH- \\
\hline SF & $2.268(\mathrm{~s})(6 \mathrm{H}) 2.284(\mathrm{~s})(6 \mathrm{H})$ & - & $6.352-8.293(\mathrm{~m})(8 \mathrm{H})$ & $10.945(\mathrm{~s})(2 \mathrm{H})$ \\
SM & $2.293(\mathrm{~s})(3 \mathrm{H}) 2.328(\mathrm{~s})(3 \mathrm{H})$ & - & $6.394-8.299(\mathrm{~m})(12 \mathrm{H})$ & $11.372(\mathrm{~s})(2 \mathrm{H})$ \\
SQ & - & $5.717(\mathrm{~b})(8 \mathrm{H})$ & $6.233-8.219(\mathrm{~m})(8 \mathrm{H})$ & - \\
\hline
\end{tabular}

Table 3: FT-IR data of the synthesized compounds in $\mathrm{cm}^{-1}$

\begin{tabular}{|c|c|c|c|c|c|c|c|c|}
\hline Compound & n (N-H) str. & n (C-H) str. Arom. & n (C-H) str. Aliph. & n $(C=N)$ str. & n $(\mathrm{C}=\mathrm{C})$ str. & n $(\mathrm{N}=\mathrm{N})$ str. & n (C-N) str. & n (C-H) bend. Arom. \\
\hline SF & $3370 \mathrm{~m}$ & $3143 \mathrm{w}$ & $2912 \mathrm{w}$ & $1620 \mathrm{~m}$ & $1597 \mathrm{~m}$ & $1473 \mathrm{~s}$ & $1303 \mathrm{~s}$ & $829 \mathrm{~s}$ \\
\hline SM & $3356 \mathrm{~m}$ & $3183 \mathrm{w}$ & $2954 \mathrm{~m}$ & $1627 \mathrm{~m}$ & $1693 \mathrm{~s}$ & $1492 \mathrm{~s}$ & $1330 \mathrm{~m}$ & $891 \mathrm{~s}$ \\
\hline SQ & $\begin{array}{l}3425 \mathrm{~m} \\
3332 \mathrm{~m}\end{array}$ & $3132 \mathrm{w}$ & - & $1616 \mathrm{~s}$ & $1597 \mathrm{~s}$ & $1496 \mathrm{~s}$ & $1284 \mathrm{~m}$ & $813 \mathrm{~s}$ \\
\hline
\end{tabular}

\section{FT-IR spectra}

FT-IR spectra of the synthesized compounds were carried out using $\mathrm{KBr}$ disc method. The characterized bands are given in Table 3.

The IR spectra of the azo-sulfa compounds were performed by the $\mathrm{KBr}$ disc method. Table 3 represents the data of the important bands of the IR spectra of SF, SM, and SQ compounds. The IR data of all compounds showed medium bands at $3425-3332 \mathrm{~cm}^{-1}$ which is characteristic of the $\mathrm{N}-\mathrm{H}$ stretching [17] of these compounds. The IR spectra of the compounds showed strong-medium bands at $1627-1616 \mathrm{~cm}^{-1}$ and $1496-1473 \mathrm{~cm}^{-1}$ which are characteristic of the $\mathrm{C}=\mathrm{N}$ and $\mathrm{N}=\mathrm{N}$ stretching, respectively [17]. The compounds showed strong-medium bands at $1330-1284 \mathrm{~cm}^{-1}$ which referred to C-N stretching. Weak absorption bands at 3183-3132 $\mathrm{cm}^{-1}$ attributed to stretching vibration of $\mathrm{C}-\mathrm{H}$ aromatic systems.

\section{Antioxidant reactivity}

The researchers used different methods for antioxidant activity assays in the literature references. Using DPPH radical scavenging activity is common method to investigate the antioxidant activities for different classes of natural and synthetic materials because it is quick and simple method.

As with the most antioxidant assays, the spectrophotometer instrument was used in the DPPH measurements at the wavelength of $517 \mathrm{~nm}$. The results indicate that, by mixing the antioxidant samples with DPPH reagent solution, the color is clearly turned from purple to yellow by time. The changing in color is determined by measuring absorbance intensity with a spectrophotometer at $517 \mathrm{~nm}$. Antioxidant results of the synthesized compounds (SF, SM, and SQ) with respect to AA are reported in Table 4.

In our study and according to chemical structural features, there were three different types of synthesized compounds. It is obvious that structural change gave clean refer vision about the bioactivity which trends to structural modification of molecules. When structure altered, the biological activity will change in a regular trend. Without exception, this has been reflected in the case of the sulfonamide group which maybe showed a tendency of antioxidant activity. We indicated that all three compounds had good antioxidant activity but less effect than AA. Table 5 refers the antioxidant activity \% of the prepared compounds which gave the values between $57.79,59.82$, and 73.69 for SQ, SM, and $\mathrm{SF}$, respectively, compared with 81.34 for AA, as shown in Fig. 4.

Furthermore, differences in the aromatic groups (pyrimidine, isoxazole, and primary amines) may be enhanced the antioxidant potency. We found that compound SF has higher $\mathrm{IC}_{50}(15.23 \mu \mathrm{g} / \mathrm{ml})$ as compared with another two compounds SM and SQ (20.71 and $21.35 \mu \mathrm{g} / \mathrm{ml}$ ), respectively, as shown in Table 5. 


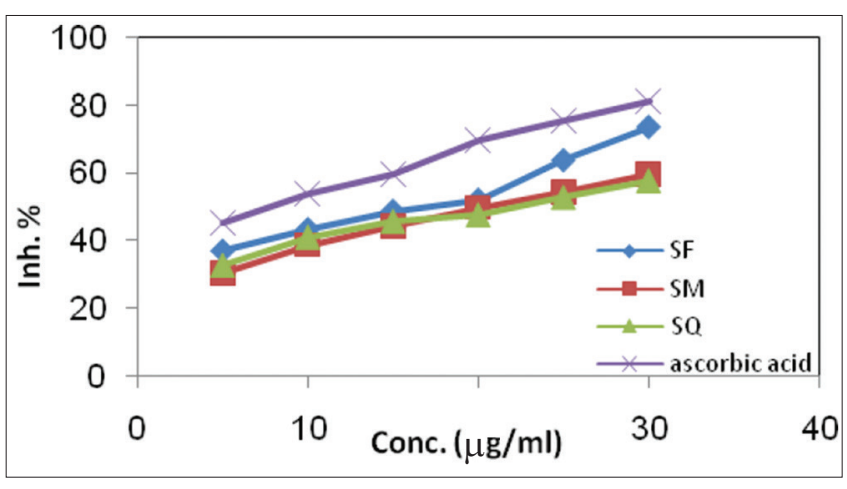

Fig. 4: Free radical scavenging effects \% of the azo-sulfa compounds and ascorbic acid at different concentrations

Table 4: Percentage inhibition of different concentrations of azo-sulfa compounds and ascorbic acid

\begin{tabular}{|c|c|c|c|c|}
\hline \multirow{2}{*}{$\begin{array}{l}\text { Concentration } \\
(\mu \mathrm{g} / \mathrm{ml})\end{array}$} & \multicolumn{4}{|l|}{ Compound } \\
\hline & SF & SM & $S Q$ & AA \\
\hline 5 & $37.11 \pm 0.02$ & $30.47 \pm 0.11$ & $33.08 \pm 0.05$ & $45.54 \pm 0.24$ \\
\hline 10 & $43.49 \pm 0.08$ & $38.89 \pm 0.35$ & $41.29 \pm 0.14$ & $54.09 \pm 0.09$ \\
\hline 15 & $48.87 \pm 0.12$ & $44.39 \pm 0.57$ & $45.91 \pm 0.22$ & $59.82 \pm 0.47$ \\
\hline 20 & $52.17 \pm 0.14$ & $49.88 \pm 0.43$ & $47.79 \pm 0.09$ & $69.70 \pm 0.37$ \\
\hline 25 & $63.89 \pm 0.11$ & $54.60 \pm 1.24$ & $52.93 \pm 0.41$ & $75.65 \pm 0.62$ \\
\hline 30 & $73.69 \pm 1.01$ & $59.82 \pm 0.51$ & $57.79 \pm 0.58$ & $81.34 \pm 0.27$ \\
\hline
\end{tabular}

Table 5: DPPH radical scavenging IC50 values of azo-sulfa compounds and ascorbic acid

\begin{tabular}{ll}
\hline Compound & IC50 value $(\boldsymbol{\mu g} / \mathbf{m l})$ \\
\hline SF & $15.23 \pm 0.11$ \\
SM & $20.71 \pm 0.23$ \\
SQ & $21.35 \pm 0.41$ \\
AA & $7.59 \pm 0.08$ \\
\hline
\end{tabular}

The present investigation emphasized mainly on two important things. One of these is to the synthesis of molecules having $\mathrm{N}$ and $\mathrm{O}$ heterocyclic moieties is determine their antioxidant efficacy. Nitrogen and oxygen-containing heterocyclic organic compounds show interesting chemical property as well as biological activity [18]. Furthermore, each of the compounds contains a high percentage of nitrogen or oxygen gave enhancement to the reactivity. Therefore, it might have enhanced the power to absorb free radicals, especially ROS and reactive nitrogen species (RNS).

\section{CONCLUSION}

Three novel symmetrically azo-sulfonamides compounds such as SF, SM, and SQ were synthesized, characterized, and evaluated for their antioxidant test. Most of the synthesized compounds showed promising antioxidant activity compared with AA, suggesting a possible clinical significance of novel compounds. Compound SF showed remarkable results as compared with the standard compound AA.

\section{REFERENCES}

1. Kolaczek A, Fusiarz I, Ławecka J, Branowska D. Biological activity and synthesis of sulfonamide derivatives: A brief review. Chemik 2014;68:620-8.

2. Chibale K, Haupt H, Kendrick H, Yardley V, Saravanamuthu A, Fairlamb $\mathrm{AH}$, et al. Antiprotozoal and cytotoxicity evaluation of sulfonamide and urea analogues of quinacrine. Bioorg Med Chem Lett 2001;11:2655-7.

3. Ali SA, Jabbir AH, Mohsie RA. Synthesis of some sulfa drug derivatives as antibacterial agents. Int J Curr Microbiol Appl Sci 2016;5:75-83.

4. Brown MA, De Vito SC. Predicting azo dye toxicity. Crit Rev Environ Sci Technol 1993:23:249-324.

5. Sahoo J, Paidesetty SK. Medicinal interest of azo-bases organic compounds: A review. Asian J Pharm Clin Res 2016;9:33-9.

6. Gil C. MSc Thesis. Toxicological Effects of Food Additives-Azo Dyes. Department of Biomedicine and Veterinary Public Health, Division of Pathology, Pharmacology and Toxicology, Swedish University of Agricultural Sciences; 2014

7. Akar Z, Küçük M, Doğan H. A new colorimetric DPPH• scavenging activity method with no need for a spectrophotometer applied on synthetic and natural antioxidants and medicinal herbs. J Enzyme Inhib Med Chem 2017;32:640-7.

8. Li X, Wu X, Huang L. Correlation between antioxidant activities and phenolic contents of radix Angelicae sinensis (Danggui). Molecules 2009;14:5349-61.

9. Gu I, Huyut Z, Elmastas M, Aboul-Enein HY. Radical scavenging and antioxidant activity of tannic acid. Arab J Chem 2010;3:43-53.

10. Santos MC, Gonçalves EC. Effect of different extracting solvents on antioxidant activity and phenolic compounds of a fruit and vegetable residue flour. Sci Agropecu 2017;7:7-14.

11. Kumawat BK, Gupta M, Singh Y. Free radical scavenging effect of various extracts of leaves of Balanites aegyptiaca (L.) Delile by DPPH method. Asian J Plant Sci Res 2012;2:323-9.

12. Saha MR, Hasan SM, Akter R, Hossain MM, Alam MS, Alam MA, et al. In vitro free radical scavenging activity of methanol extract of the leaves of Mimusops elengi Linn. Bangladesh J Vet Med 2008;6:197-202.

13. Fayadh RH, Ali AA, Al-Jabri FM. Synthesis and identification symmetrically azo dyes derived from sulfa compounds and spectrophotometric study of nickel (II) complexes with prepared dyes. Int J Eng Tech Res 2015;3:24-8.

14. Proestos C, Lytoudi K, Mavromelanidou OK, Zoumpoulakis P, Sinanoglou VJ. Antioxidant capacity of selected plant extracts and their essential oils. Antioxidants (Basel) 2013;2:11-22.

15. Gaber AE, El-Gaby MS, El-Dean AM, Eyada HA, Al-Kamali AS. Synthesis of novel polyfunctionally substituted thieno[2,3-c] pyridazines. J Chin Chem Soc 2004;51:1325-31.

16. Al-Sahlanee TM, Al-Amery M. Synthesis, characterization, antioxidant and anticancer human studies of new metal ion complexes of poly schiff base derived from 4-aminoacetophenone with salicylaldehyde and 4-bromoaniline. Asian J Pharm Clin Res 2018;11:489-93.

17. Silverstein RM, Webster FX. Spectroscopic Identification of Organic Compounds. $6^{\text {th }}$ ed. New York: John Wiley and Sons; 1998.

18. Hossain MM, Shaha SK, Aziz F. Antioxidant potential study of some synthesized N-heterocycles. Bangladesh Med Res Counc Bull 2009;35:49-52. 